\title{
Morphological distinction and sexual dimorphism in divergent clades of Neurergus kaiseri (Amphibia: Salamandridae)
}

\author{
Hadi Khoshnamvand, Mansoureh Malekian*, Yazdan Keivany \\ Department of Natural Resources, Isfahan University of Technology, 8415683111, Isfahan, Iran. \\ *Correspondence: Phone: +9833911024, Fax: +9833912840, E-mail: mmalekian@cc.iut.ac.ir
}

Received: 11 April 2018; returned for review: 28 June 2018; accepted: 19 September 2018.

Morphological differentiation and sexual dimorphism in the two genetically distinct clades (Northern and Southern clades) of the Lorestan newt, Neurergus kaiseri, was evaluated for 72 live specimens, using five body- and nine head-related characters and eight calculated ratios. Principle component analysis of morphological characters confirmed that the Lorestan newt populations are well separated into two distinct groups, suggesting that a taxonomic revision in N. kaiseri may be required because of significant molecular, morphological and ecological differences between these clades. Sexual dimorphism in N. kaiseri includes body size and shape. Females were clearly larger than males in most body- and head-related variables and males had relatively greater head width and eye length. Sexual dimorphism in this species may be linked to sexual selection and ecological differences between sexes. However, many aspects of the ecology and reproductive biology of this species remain unknown.

Key words: endangered species; morphology; newt; southwestern Iran.

Sexual dimorphism is very common in the animal kingdom, but its magnitude and direction (male-typical or femaletypical direction) are highly variable across species (FAIRBAIRN, 1997; FAIRBAIRN et al., 2007). The evolutionary significance of sexual dimorphism can be explained by two major factors including sexual and fecundity selection (DARwIN, 1871). Sexual selection seems to be the most significant factor for sexual dimorphism (HowARD \& Kluge, 1985; Andersson, 1994; Derocher et al., 2005; Kaliontzopoulou et al., 2007; Fontenot \& Seigel, 2008). Ecological aspects such as the utilization of resources through niche partitioning can also con- tribute (Shine, 1989). For example, different feeding strategies can cause differences in head morphology (MALMgren \& THOLLESSON, 1999). Large males can have advantage when fighting other males or protecting resources, which increases their chances of mating and consequently their reproductive success (Kupfer, 2007). Large body size can also enhance the reproductive success of females, as clutch size or the size of eggs and offspring increases with female size (BLANCKENHORN, 2005).

Sexual dimorphism is present in many amphibian species (SHINE, 1979), involving several dimorphic traits such as body size, glandular development and coloration 
(Duellman \& Trueb, 1994). Much attention has been paid to the sexual dimorphism of salamanders, describing the evolutionary processes that are thought to drive such dimorphism (e.g. Halliday \& Arano, 1991; Kalezic et al., 1992; Malmgren \& TholLesson, 1999; Serra-Сobo et al., 2000; KupFER, 2007; Ivanović \& Kalezić, 2012). In salamanders, females are generally larger than males and female body size is usually correlated with clutch size (Duellman \& Trueb 1986; Kalezic et al., 1992), while male -biased dimorphism may be attributed to agonistic behavior of males such as combating during the breeding season (SHINE, 1989). Some studies demonstrate that sexual dimorphism occurs not only in body size, but also in body shape (MALmgren \& Thollesson, 1999; Hasumi, 2010; Zhang et al., 2014) or in the tail (e.g. Liu et al., 1960). For example, in the Hymalian newt (Tylototriton verrucosus) females are significantly longer and heavier than males, while males have bigger cloacae and longer tails than females (SEglie et al., 2010).

Different expressions of sexual size dimorphism have been observed in newts (Reinhard \& Kupfer, 2015), suggesting that more than one evolutionary model work simultaneously on different traits and influence the diversity of forms. Natural and sexual selection interact and determine the type and the degree of sexual dimorphism, therefore sexual dimorphism is often regarded as a life-history adaptation (Ficetola et al., 2013).

Asian salamanders, including the Middle East genus Neurergus, are amongst the less studied amphibian species. The Lorestan newt (Neurergus kaiseri, Schmidt 1952) is endemic to the southern Zagros mountains of Iran, inhabiting streams and ponds in open woodlands dominated by oak trees (Quercus brantii). It is classified as vulnerable (VU) by the IUCN Red List and listed in the Appendix I of the Convention on International Trade in Endangered Species (CITES). It is threatened by several factors like illegal trading, drought, and climate change (IUCN, 2018). Sharifi et al. (2012) reported sexual size dimorphism in body-related characters of Lorestan newts, but not in head-related characters. However, the newt samples from different populations analyzed in that study were pooled and the locality of the collected specimens was not reported, which did not allow for evaluating whether sexual dimorphism varied among populations and geographic areas, as has been reported in salamanders (e.g. Ivanović et al., 2008; Ivanović \& Kalezić, 2012). Further, a genetic study based on the variation of mtDNA (D-loop) (FARASAT

Table 1: Description of the sites sampled in the current study.

\begin{tabular}{lccccc}
\hline & Site name & Altitude (m) & $\begin{array}{c}\text { Geographical } \\
\text { coordinates }\end{array}$ & Female & Male \\
\hline Northern clade & Kerser & 1100 & $3^{\circ} 06^{\prime} \mathrm{N}, 48^{\circ} 01^{\prime} \mathrm{E}$ & 9 & 5 \\
& Tafav & 1350 & $32^{\circ} 55^{\prime} \mathrm{N}, 48^{\circ} 01^{\prime} \mathrm{E}$ & 8 & 6 \\
& Vejenab & 950 & $33^{\circ} 00^{\prime} \mathrm{N}, 48^{\circ} 04^{\prime} \mathrm{E}$ & 4 & 5 \\
\multirow{5}{*}{ Southern clade } & & & & & \\
& & & & & \\
& Talezang & 980 & $32^{\circ} 45^{\prime} \mathrm{N}, 48^{\circ} 50^{\prime} \mathrm{E}$ & 9 & 7 \\
& Tova & 940 & $32^{\circ} 06^{\prime} \mathrm{N}, 48^{\circ} 45^{\prime} \mathrm{E}$ & 8 & 11 \\
\hline
\end{tabular}


Figure 1: Sampling locations and pictures of Neurergus kaiseri from the Southern (black ellipses) and Northern (open diamonds) clades. (a) Male, Southern clade. (b) Female, Southern clade. (c) Male, Northern clade. (d) Female, Southern clade.
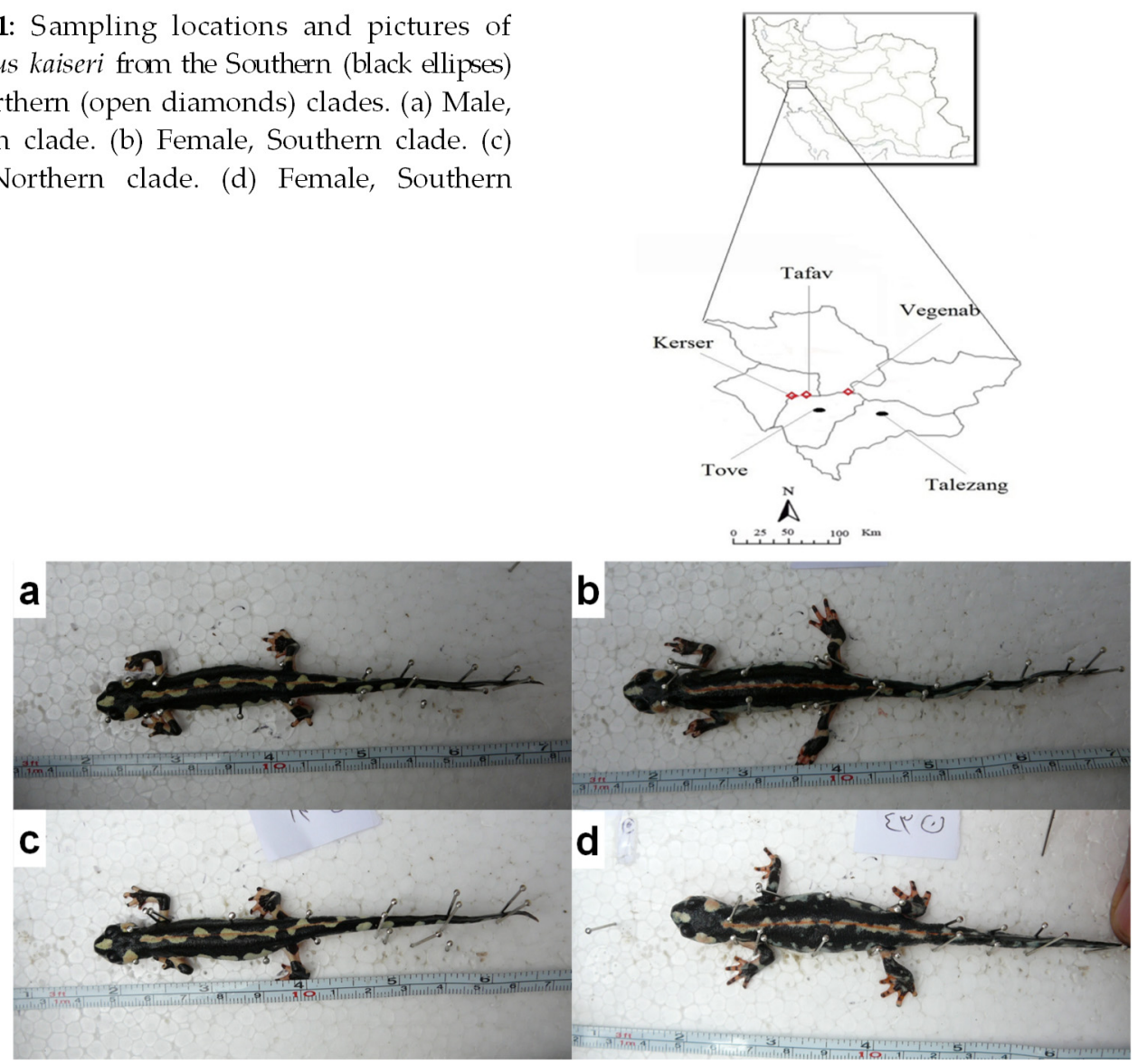

et al., 2016) revealed the presence of two genetically distinct clades (Northern and Southern clades) and a high geographical structuring within the Lorestan newt. Populations of the two clades have been isolated for about 1.5 million years and their habitats differ in temperature and precipitation (FARAsAt et al., 2016). No previous studies have investigated morphological differences of these lineages. In the present study, we aimed to (i) investigate morphological differentiation between the two genetically identified clades (Northern and Southern clades), and (ii) explore the inter- sexual differences in both Northern and Southern clades.

\section{Materials and Methods}

We sampled 34 males and 38 females of the Lorestan newt from five sites, including the Northern and Southern clades (FARAsAt et al., 2016) in the southern Zagros mountain range (Fig. 1). Three sites were selected from the Northern clade and two sites from the Southern clade (Table 1). These sites are separated from each other by steep and rocky mountains. Drought in the past few years has dried several sites 


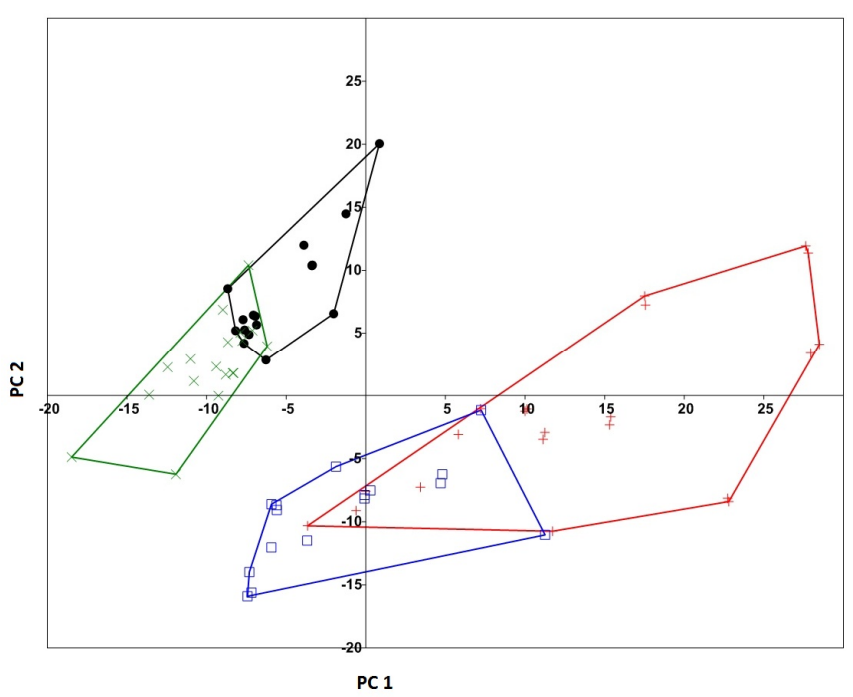

Figure 2: Scatter plot for the first two principal components (PC) obtained from a principal component analysis of 14 morphological characters measured in Neurergus kaiseri, including convex polygons grouping individuals according to their clade and sex. Xs (x) represent Southern clade males, black circles $(\bullet)$ represent Southern clade females, open squares ( $\square$ ) represent Northern clade males, and crosses (+) represent Northern clade females. in the region and reduced the number of sample sites relative to what was sampled by FARAsAt et al. (2016). We measured 18 males and 17 females from the Southern clade and 16 males and 21 females from the Northern clade (Table 1).

We captured individuals using a dip net and measured them alive without anesthesia. They were first sexed based on cloacal morphology. The male has a fleshy protuberance at the anterior end of the vent slit, while the female lacks the protuberance. We measured 14 variables including five body- and nine head-related metrics using dial calipers to the nearest 0.01 $\mathrm{mm}$. The following measurements were taken: total body length (BL), snout-vent length (SVL), tail length (TL), right front leg length (FLL), right hind leg length (HLL), height of head $(\mathrm{HH})$, head length (HL), head width (HW), distance between nostrils (IN), right eye length (ER), nasal tip to right eye distance (END), interorbital distance (IO), nostril to right eye distance (NED), and mouth length (ML).
In order to reduce measurement error, only one observer conducted all measurements, which were each repeated three times and averaged to represent each individual. Once measurements were taken, all the individuals were released at the point of capture. Later, we computed eight body ratios commonly used in newts (ÇIÇEK et al., 2011) including BL-HL, BL-TL, BL-SVL, TL-SVL, BL-HW, HW-HL, HWER, and SVL-HW.

We tested the normality for distribution of all characters using the D'Agostino and Pearson omnibus normality test (ÖztunA et al., 2006). In order to investigate the degree of morphological differences within samples we run a Principal Component Analysis (PCA) with the 14 morphological parameters. To determine which variables showed differences, we conducted a two-way multivariate analysis of the variance (MANOVA) with sex and clade as factors and all morphometric characters as independent variables. Additionally, to adjust the characters to body-head size, a 


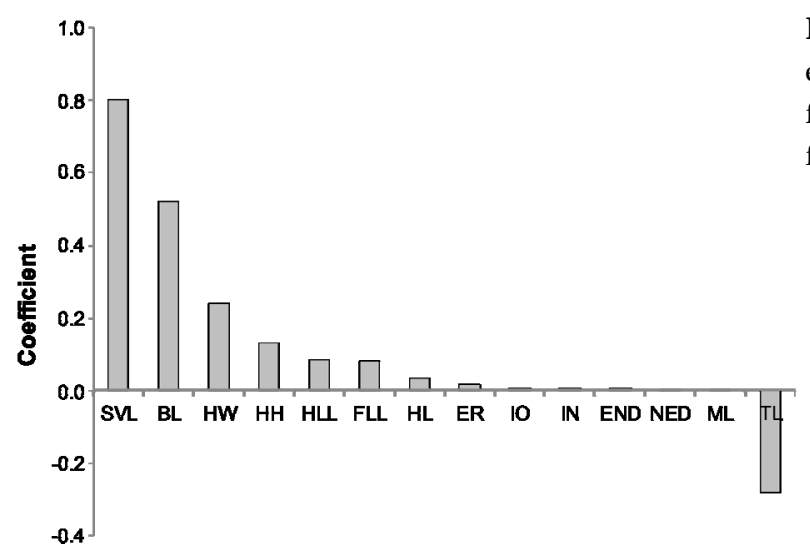

Figure 3: Coefficients of association of each morphometric character with the first principal component (PC1). See text for abbreviations.

Table 2: Mean ( \pm standard deviation) of each morphological character measured in Neurergus kaiseri individuals from the Northern and Southern clades (see text for abbreviations). All measurements are shown in millimeters. Results of the analysis of the variance to compare measurements between clades are shown. Variables for which significant differences were obtained are highlighted in bold.

\begin{tabular}{cccccc}
\hline Character & $\begin{array}{c}\text { Northern } \\
\text { clade }\end{array}$ & $\begin{array}{c}\text { Southern } \\
\text { clade }\end{array}$ & $\begin{array}{c}\text { Sum of } \\
\text { squares }\end{array}$ & F1,86 & $\boldsymbol{P}$ \\
\hline SVL & $72.48 \pm 1.45$ & $60.13 \pm 0.43$ & 2742.08 & 63.35 & $<\mathbf{0 . 0 0 1}$ \\
TL & $53.83 \pm 0.55$ & $66.27 \pm 0.44$ & 2800.14 & 313.40 & $<\mathbf{0 . 0 0 1}$ \\
BL & $125.65 \pm 1.51$ & $126.28 \pm 0.83$ & 0.00 & 0.00 & 0.993 \\
FLL & $22.48 \pm 0.2$ & $21.24 \pm 0.16$ & 25.17 & 19.81 & $<\mathbf{0 . 0 0 1}$ \\
HLL & $23.12 \pm 0.21$ & $21.65 \pm 0.19$ & 35.12 & 22.18 & $<\mathbf{0 . 0 0 1}$ \\
HH & $4.44 \pm 0.07$ & $4.39 \pm 0.07$ & 0.071 & 0.36 & 0.552 \\
HL & $13.21 \pm 0.09$ & $16.6 \pm 0.09$ & 209.32 & 684.11 & $<\mathbf{0 . 0 0 1}$ \\
HW & $10.38 \pm 0.1$ & $11.04 \pm 0.07$ & 8.33 & 25.13 & $<\mathbf{0 . 0 0 1}$ \\
IN & $3.03 \pm 05$ & $3.09 \pm 0.02$ & 0.09 & 1.18 & 0.281 \\
ER & $4.43 \pm 0.06$ & $4.55 \pm 0.05$ & 0.38 & 2.76 & 0.101 \\
END & $5.21 \pm 0.02$ & $5.67 \pm 0.04$ & 3.79 & 84.69 & $<\mathbf{0 . 0 0 1}$ \\
NED & $4.05 \pm 0.01$ & $4.16 \pm 0.02$ & 0.23 & 12.14 & $\mathbf{0 . 0 0 1}$ \\
IO & $6.28 \pm 0.06$ & $6.47 \pm 0.07$ & 0.75 & 3.24 & 0.076 \\
ML & $10 \pm 0.02$ & $10.15 \pm 0.04$ & 0.39 & 8.66 & $\mathbf{0 . 0 0 4}$ \\
BL-HL & $9.56 \pm 0.07$ & $7.54 \pm 0.07$ & 68.93 & 450.55 & $<\mathbf{0 . 0 0 1}$ \\
BL-TL & $2.34 \pm 0.03$ & $1.9 \pm 0.00$ & 3.62 & 163.77 & $<\mathbf{0 . 0 0 1}$ \\
BL-SVL & $1.74 \pm 0.03$ & $2.09 \pm 0.00$ & 2.17 & 377.46 & $<\mathbf{0 . 0 0 1}$ \\
TL-SVL & $0.74 \pm 0.01$ & $1.1 \pm 0.01$ & 2.20 & 369.72 & $<\mathbf{0 . 0 0 1}$ \\
BL-HW & $12.19 \pm 0.14$ & $11.43 \pm 0.12$ & 10.28 & 16.05 & $<\mathbf{0 . 0 0 1}$ \\
HW-HL & $0.78 \pm 0.00$ & $0.66 \pm 0.01$ & 0.26 & 195.04 & $<\mathbf{0 . 0 0 1}$ \\
HW-ER & $2.35 \pm 0.03$ & $2.43 \pm 0.02$ & 0.09 & 2.58 & 0.113 \\
SVL-HW & $6.99 \pm 0.12$ & $5.45 \pm 0.06$ & 42.62 & 125.16 & $<\mathbf{0 . 0 0 1}$ \\
\hline & & & & &
\end{tabular}


multivariate analysis of the covariance (MANCOVA) of biometric data with SVL as a covariate was performed. When significant factor effects were found, further simple effect tests were performed and Bonferroni adjustment for multiple comparisons was applied. The sexual dimorphism index (SDI, Gibbons \& Lovich, 1990) was calculated as the quotient between the mean SVL of the largest sex (SVLlarge) and the mean SVL of the smallest sex (SVLsmall) minus 1 (SDI = [SVLlarge / SVLsmall] - 1). A discriminant function analysis (DFA) was conducted to identify morphological characters differing between sexes in each clade. Statistical analyses were conducted using the software package SPSS (version 21) with the exception of DFA and PCA, which were performed in Minitab 17 and PAST 3.14, respectively.

\section{Results}

The PCA based on the morphological characters confirmed that the sampled populations are well separated into two distinct groups, corresponding to the two genetic clades (Fig. 2). The first principal component (PC1) explained $66 \%$ of the total variance and the morphological parameters more associated with this $\mathrm{PC} 1$ were SVL, BL, TL, HW and $\mathrm{HH}$ (Fig 3).

The MANOVA indicated that clade (Wilks' lambda $=0.011, \mathrm{~F}_{1,21}=1.84, P<$ 0.001 ) and sex (Wilks' lambda $=0.32, \mathrm{~F}_{1,21}=$ $4.55, P<0.001$ ) had significant effects on morphological character variation. Moreover, a significant clade $\mathrm{x}$ sex interaction was observed (Wilks' lambda $=0.41, \mathrm{~F}_{1,21}=3.01$, $P=0.001)$, indicating a divergence of sexual dimorphism between clades. The majority of variables were significantly different between clades (Table 2). Individuals from the Northern clade showed significantly higher values of SVL, FLL and HLL, while individuals from the Southern clade had higher TL, HL, HW, END, NED and ML ( $P$ $<0.05$, Table 2).

Results of the MANOVA simple effect test for the clade $x$ sex interaction, based on estimated marginal means, showed that females in both clades were significantly larger than males for most body- and head -related variables. Females were significantly larger than males in SVL, BL, HLL, HL and ML in both clades. In addition, Southern clade females were larger than males in TL and IO, and Northern clade females were significantly larger than males in FLL and HH. Males of both clades were significantly larger than females in HW (Table 3). The MANCOVA supported the results indicating that, in the Northern and Southern clades, females were relatively larger than males in most head and body-related characters and males had relatively larger HW and ER than males (Fig. 4 a-f). The SDI was 0.054 for the Southern clade and 0.18 for the Northern clade. When BL was used instead of SVL to calculate SDI values, these were 0.054 for the Southern clade and 0.101 for the Northern clade.

The DFA showed significant differences between males and females in each clade (Northern clade: Hotelling's $\mathrm{T}^{2}=$ 66.4, $\mathrm{F}_{1,21}=2.97, P=0.01$; Southern clade: Hotelling's $\mathrm{T}^{2}=100.9, \mathrm{~F}_{1,21}=4.5, P=0.001$, Fig. 5). Further investigation of the variables revealed that only NED and nostril to eye distance END showed small overlap between sexes. 
Table 3: Results of MANOVA simple effect test based on estimated marginal means between adult males and females of Neurergus kaiseri within each of the clades the (N: Northern, S: Southern) of the 14 morphometric characters and eight ratios analyzed in the study (see text for abbreviations and Table 1 for sample sizes). Marginal mean differences and P-values obtained after Bonferroni adjustment for multiple comparisons are shown.

\begin{tabular}{|c|c|c|c|c|c|}
\hline Character & Clade & \% (Mean \pm SE) & $\sigma^{\prime}($ Mean \pm SE $)$ & Mean difference $\$$ - $\sigma^{\prime}( \pm$ SE) & $P$ \\
\hline \multirow[t]{2}{*}{ SVL } & $\mathrm{N}$ & $77.5 \pm 1.7$ & $65.5 \pm 1.1$ & $11.90 \pm 1.64$ & $<0.001$ \\
\hline & $S$ & $61.8 \pm 0.5$ & $58.6 \pm 0.5$ & $3.18 \pm 1.67$ & 0.041 \\
\hline \multirow[t]{2}{*}{$\mathrm{TL}$} & $\mathrm{N}$ & $53.9 \pm 0.9$ & $53.8 \pm 0.6$ & $0.16 \pm 0.96$ & 0.870 \\
\hline & S & $67.6 \pm 0.6$ & $65.0 \pm 0.5$ & $2.61 \pm 0.97$ & 0.009 \\
\hline \multirow[t]{2}{*}{ BL } & $\mathrm{N}$ & $131.5 \pm 1.8$ & $119.3 \pm 1.1$ & $12.11 \pm 1.90$ & $<0.001$ \\
\hline & S & $129.4 \pm 0.1$ & $123.4 \pm 0.9$ & $6.02 \pm 1.93$ & 0.003 \\
\hline \multirow[t]{2}{*}{ FLL } & $\mathrm{N}$ & $23.0 \pm 0.3$ & $21.6 \pm 0.2$ & $1.29 \pm 0.34$ & $<0.001$ \\
\hline & $S$ & $21.5 \pm 0.2$ & $20.1 \pm 0.2$ & $0.51 \pm 0.35$ & 0.144 \\
\hline \multirow[t]{2}{*}{ HLL } & $\mathrm{N}$ & $23.6 \pm 0.3$ & $22.2 \pm 0.3$ & $1.28 \pm 0.38$ & 0.001 \\
\hline & S & $22.0 \pm 0.2$ & $21.3 \pm 0.3$ & $0.74 \pm 0.39$ & 0.044 \\
\hline \multirow[t]{2}{*}{$\mathrm{HH}$} & $\mathrm{N}$ & $4.6 \pm 0.6$ & $4.2 \pm 0.1$ & $0.43 \pm 0.14$ & 0.003 \\
\hline & S & $4.4 \pm 0.1$ & $4.3 \pm 0.1$ & $0.10 \pm 0.14$ & 0.472 \\
\hline \multirow[t]{2}{*}{$\mathrm{HL}$} & $\mathrm{N}$ & $13.5 \pm 0.1$ & $12.8 \pm 0.5$ & $0.69 \pm 0.16$ & $<0.001$ \\
\hline & $S$ & $16.8 \pm 0.1$ & $16.5 \pm 0.1$ & $0.31 \pm 0.16$ & 0.047 \\
\hline \multirow[t]{2}{*}{ HW } & $\mathrm{N}$ & $10.1 \pm 0.1$ & $10.5 \pm 0.1$ & $0.44 \pm 0.18$ & 0.019 \\
\hline & $S$ & $10.9 \pm 0.1$ & $11.3 \pm 0.1$ & $0.39 \pm 0.19$ & 0.050 \\
\hline \multirow[t]{2}{*}{ IN } & $\mathrm{N}$ & $3.1 \pm 0.1$ & $2.9 \pm 0.1$ & $0.14 \pm 0.09$ & 0.115 \\
\hline & $S$ & $3.2 \pm 0.0$ & $3.0 \pm 0.0$ & $0.15 \pm 0.09$ & 0.108 \\
\hline \multirow[t]{2}{*}{ ER } & $\mathrm{N}$ & $4.5 \pm 0.1$ & $4.2 \pm 0.0$ & $0.34 \pm 0.17$ & 0.065 \\
\hline & S & $4.6 \pm 0.1$ & $4.5 \pm 0.1$ & $0.08 \pm 0.12$ & 0.492 \\
\hline \multirow[t]{2}{*}{ END } & $\mathrm{N}$ & $5.4 \pm 0.0$ & $5.2 \pm 0.0$ & $0.10 \pm 0.07$ & 0.146 \\
\hline & $S$ & $5.7 \pm 0.1$ & $5.6 \pm 0.0$ & $0.10 \pm 0.07$ & 0.146 \\
\hline \multirow[t]{2}{*}{ NED } & $\mathrm{N}$ & $4.1 \pm 0.0$ & $4.2 \pm 0.0$ & $-0.01 \pm 0.04$ & 0.894 \\
\hline & $S$ & $4.2 \pm 0.0$ & $4.1 \pm 0.1$ & $0.07 \pm 0.05$ & 0.142 \\
\hline \multirow[t]{2}{*}{ IO } & $\mathrm{N}$ & $6.3 \pm 0.0$ & $6.2 \pm 0.0$ & $0.11 \pm 0.15$ & 0.471 \\
\hline & $S$ & $6.7 \pm 0.1$ & $6.1 \pm 0.0$ & $0.46 \pm 0.15$ & 0.004 \\
\hline \multirow[t]{2}{*}{ ML } & $\mathrm{N}$ & $10.1 \pm 0.0$ & $10.0 \pm 0.0$ & $0.09 \pm 0.06$ & 0.090 \\
\hline & S & $10.4 \pm 0.1$ & $10.0 \pm 0.0$ & $0.36 \pm 0.06$ & $<0.001$ \\
\hline \multirow[t]{2}{*}{ BL-HL } & $\mathrm{N}$ & $9.8 \pm 0.1$ & $9.3 \pm 0.0$ & $0.41 \pm 0.12$ & 0.001 \\
\hline & $S$ & $7.6 \pm 0.1$ & $7.5 \pm 0.1$ & $0.22 \pm 0.12$ & 0.074 \\
\hline \multirow[t]{2}{*}{ BL-TL } & $\mathrm{N}$ & $2.5 \pm 0.4$ & $2.2 \pm 0.0$ & $0.22 \pm 0.04$ & $<0.001$ \\
\hline & S & $2.0 \pm 0.0$ & $1.9 \pm 0.0$ & $0.016 \pm 0.04$ & 0.717 \\
\hline \multirow[t]{2}{*}{ BL-SVL } & $\mathrm{N}$ & $1.7 \pm 0.0$ & $1.8 \pm 0.0$ & $-0.12 \pm 0.02$ & $<0.001$ \\
\hline & $S$ & $2.1 \pm 0.0$ & $2.1 \pm 0.0$ & $-0.01 \pm 0.02$ & 0.607 \\
\hline \multirow[t]{2}{*}{ TL-SVL } & $\mathrm{N}$ & $0.7 \pm 0.2$ & $0.8 \pm 0.0$ & $-0.12 \pm 0.02$ & $<0.001$ \\
\hline & $S$ & $1.1 \pm 0.0$ & $1.1 \pm 0.0$ & $-0.02 \pm 0.02$ & 0.487 \\
\hline \multirow[t]{2}{*}{ BL-HW } & $\mathrm{N}$ & $12.5 \pm 0.1$ & $11.8 \pm 0.1$ & $0.67 \pm 0.23$ & 0.005 \\
\hline & S & $12.0 \pm 0.1$ & $11.0 \pm 0.1$ & $0.89 \pm 0.24$ & $<0.001$ \\
\hline \multirow[t]{2}{*}{ HW-HL } & $\mathrm{N}$ & $0.8 \pm 0.0$ & $0.8 \pm 0.0$ & $-0.01 \pm 0.01$ & 0.480 \\
\hline & $S$ & $0.6 \pm 0.0$ & $0.7 \pm 0.0$ & $-0.03 \pm 0.01$ & 0.008 \\
\hline \multirow[t]{2}{*}{ HW-ER } & $\mathrm{N}$ & $2.3 \pm 0.0$ & $2.4 \pm 0.0$ & $-0.09 \pm 0.06$ & 0.140 \\
\hline & S & $2.4 \pm 0.0$ & $2.5 \pm 0.2$ & $-0.11 \pm 0.06$ & 0.071 \\
\hline \multirow[t]{2}{*}{ SVL-HW } & $\mathrm{N}$ & $7.4 \pm 0.2$ & $6.5 \pm 0.0$ & $0.86 \pm 0.16$ & $<0.001$ \\
\hline & S & $5.7 \pm 0.1$ & $2.2 \pm 0.2$ & $0.45 \pm 0.16$ & 0.006 \\
\hline
\end{tabular}




\section{Discussion}

Morphological analyses confirmed the distinction of the two genetically identified clades of $N$. kaiseri (the Northern and Southern clades, FARASAT et al., 2016). Ecological differences also exist in their habi- tats. Northern clade populations are located at higher elevations and in a more humid climate than the Southern clade ones. The average elevation and annual precipitation received by the Northern and Southern clades are $1050 \mathrm{~m}$ and $670 \mathrm{~mm}$, and $870 \mathrm{~m}$ and $450 \mathrm{~mm}$, respectively. In addi-
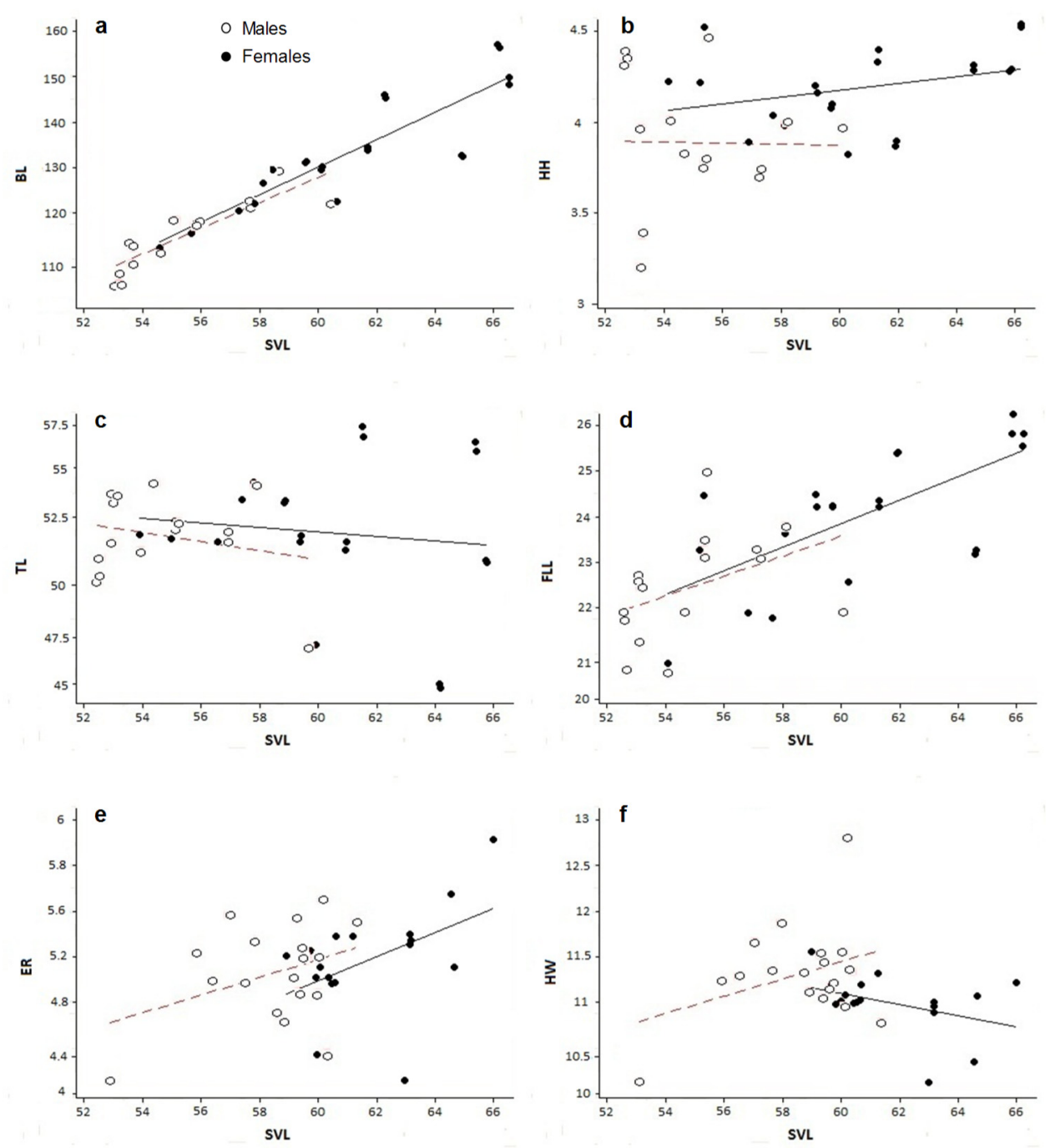

Figure 4: Examples of sexual dimorphism, as a function of the snout vent length (SVL), of Neurergus kaiseri in (a) body length, (b) head height, (c) tail length, (d) front leg length, (e) eye length, and (f) head width. Continuous and dashed lines represent the best adjustment between SVL and the compared characters for females and males, respectively. 

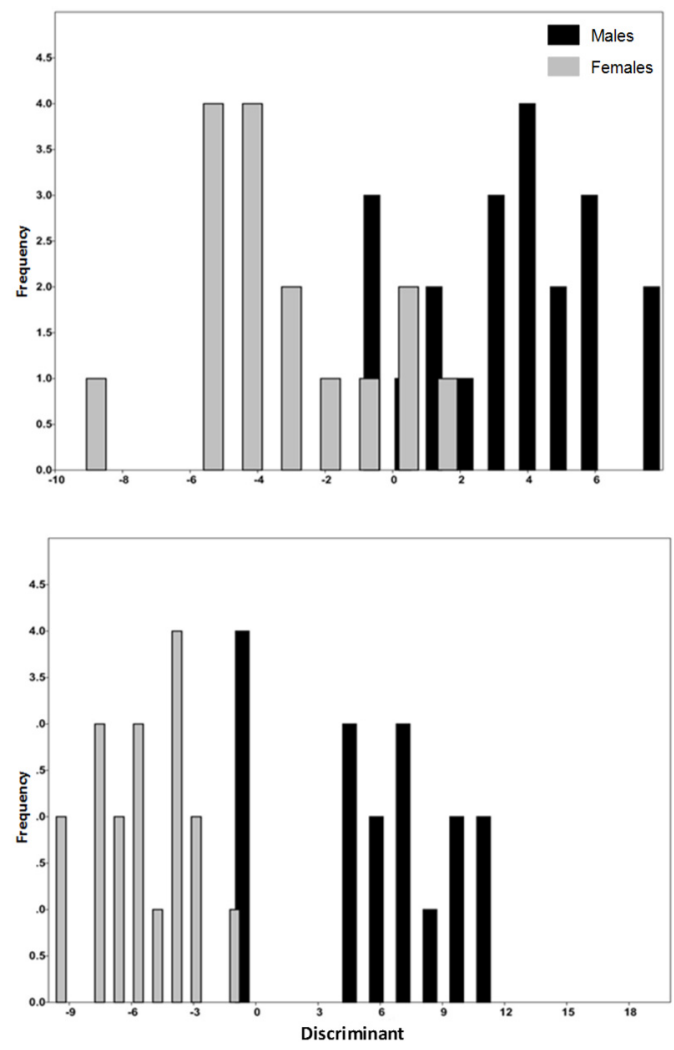

Figure 5: Graphical representation of the discriminant function analysis based on morphological characters to separate Neurergus kaiseri males and females from either the Northern (top) or Southern (bottom) clades

tion, habitats of the Southern clade are mainly streams with fast-flowing water, while habitats for the Northern clade are mostly ponds and springs with standing water. Morphological differences between the two clades can be attributed to local habitats and climates. For example, significantly longer tails and larger heads in the Southern clade compared to the Northern one could be an adaptation to flowing water to increase their ability to swim against the water flow, as suggested for some European newts (Ichthyosauria alpestris,
Ommatotriton vittatus and Lissotriton boscai) in which the evolution of longer tails might be associated with a pattern to maximize swimming speed (GvožDík \& VAN DAmme, 2006). Based on the molecular (FARAsAt et al., 2016), morphological and ecological differences between these clades, further research for a taxonomic revision in N. kaiseri is recommended.

Our analyses showed that females of both clades were clearly larger than males. Previous research also reported that females have greater mass, tail length, limb length, snout to vent length, and total length (Schmidt, 1952; SHARIFi et al., 2012). The pattern of females being larger than males is the most common in salamander species (e.g. SHIne, 1979; SAlvidio \& BRUCE, 2006; Ivanović et al., 2008; Romano et al., 2009; SegLie et al., 2010), and is influenced by sexual selection, life history and ecological differences between sexes (BAKKEGARD \& Guyer, 2004).

Sexual dimorphism in body size in $N$. kaiseri may support the fecundity-advantage model (SHINe, 1988), where larger females are able to produce more offspring to increase their reproductive success. SVL directly affects the length of the pleuroperitoneal cavity, which provides space for maturing eggs and enhances female reproductive success (Kalezic et al., 1992; Malmgren \& Thollesson, 1999). It has been reported in other newt species that females have significantly longer lifespan as well as a delayed sexual maturity relative to males (e.g. ЈАков et al., 2002), suggesting that early sexual maturation in males is reached at expenses of a small adult size, whereas a delayed sexual maturity is advantageous for female fecundi- 
ty (e.g. Marzona et al., 2004). Such a fecundity-related female-biased sexual dimorphism is common in amphibians in general, and in Salamandridae in particular (e.g. Reinhard \& Kupfer, 2013). In amphibians, the role of selecting an increased fecundity to favor large females may be reflected by the positive associations between reproductive output (i.e. clutch size, egg size, and total clutch volume) and female size (Wells, 2007).

Head size (HL and $\mathrm{HH}$ ) of female $N$. kaiseri was relatively greater than that of males. In many salamander species, males have a larger head size than females (e.g. Bovero et al., 2003, BaKKegard \& GUYER, 2004; Fontenot \& Seigel, 2008; Hasumi, 2010). However, in Neurergus microspilotus, comparatively greater head size has been reported for females (Rastegar-Pouyani $e t$ al., 2013). Sexual dimorphism in head size of $N$. kaiseri may result from reproductive roles and ecology. Females are responsible for a larger reproductive investment than males (Duellman \& Trueb, 1994), and therefore a large head should maximize energy intake (Selander, 1972; Shine, 1989; Malmgren \& Thollesson, 1999). Differences in headrelated characters may also support the hypothesis that differences in food resource usage (i.e. different feeding strategies) along with a niche divergence process have developed in N. kaiseri (Slatkin, 1984; Shine, 1989; Andersson, 1994). In newts, intersexual differences in food preferences have been reported (e.g. Lizana et al., 1986). Individuals of both sexes have adapted to different resource utilization patterns through niche partitioning (Malmgren \& Thollesson, 1999), resulting in differences of diet and prey size (e.g.
Bovero et al., 2003; Fontenot \& Seigel, 2008; Seglie et al., 2010). Differences between males and females in diet and prey size reduce intersexual food competition (Serra-Сово et al., 2000). For example in Triturus carnifex, the number of taxa in the female stomachs was twice that of the males (Romano et al., 2012). Further diet analyses $N$. kaiseri are required to quantify differences in diet and prey size between males and females.

Our results also showed that females had larger limb size (HLL and FLL) than males, which might allow them for specializing in different microhabitats (e.g. ButLer et al., 2007). However, given the lack of ecological data for the two sexes in this species, this hypothesis is difficult to evaluate.

Males of N. kaiseri in both clades showed greater HW and ER than females. This increased relative head size in males probably affects feeding habits as well as success in male-male interactions to access females and gain mating opportunities (e.g. Hasumi, 2001; Bakkegard \& Guyer, 2004; Marvin, 2009). Lorestan newts, like most other members of the family Salamandridae, have large eyes that are adapted to function in and out of the water, and vision is a key sensory organ used in mating; thus, having large eyes might be an advantage for males in order to detect and identify females (SРARreboom et al., 2000).

In conclusion, sexual dimorphism in $N$. kaiseri includes body size and shape. The sexual dimorphism of body size can be attributed to sexual and fecundity selection. Differences between males and females in head size may be attributed to 
ecological factors like niche partitioning leading to different resource usage and feeding strategies. Few studies have explored this topic in this species, and hence our findings can be a basis for future studies.

\section{REFERENCES}

Andersson, M. (1994). Sexual Selection. Princeton University Press, Princeton, New Jersey, USA.

BAKKEgARD, K.A. \& GuYer, C. (2004). Sexual size dimorphism in the red hills salamander, Phaeognathus hubrichti (Caudata: Plethodontidae: Desmognathinae). Journal of Herpetology 38: 8-15.

BLANCKENHORN, W.U. (2005). Behavioral causes and consequences of sexual size dimorphism. Ethology 111: 977-1016.

Bovero, S.; Sotgiu, G.; Castellano, S. \& GiacoMA, C. (2003). Age and sexual dimorphism in a population of Euproctus platycephalus (Caudata: Salamandridae) from Sardinia. Copeia 2003: 149-154.

Butler, M.A.; SAwyer, S.A. \& Losos, J.B. (2007). Sexual dimorphism and adaptive radiation in Anolis lizards. Nature 447: 202-205.

ÇıçeK, K.; Ayaz, D. \& Bayrakci, Y. (2011). Morphology of the northern banded newt, Ommatotriton ophryticus (Berthold, 1846) (Caudata: Salamandridae) in Uludağ (Bursa, Turkey). Herpetology Notes 4: 161165.

Darwin, C. (1871). The Descent of Man and Selection in Relation to Sex. John Murray, London, UK.

Derocher, A.E.; Andersen, M. \& WiIG, Ø. (2005). Sexual dimorphism of polar bears. Journal of Mammalogy 86: 895-901.

Duellman, W.E. \& Trueb, L. (1986). Biology of Amphibians. McGraw-Hill, New York, USA.

Duellman, W.E. \& Trueb, L. (1994). The Biology of Amphibians, $2^{\text {nd }}$ ed. John Hopkins University Press, Baltimore, Maryland, USA.

FAirbairn, D.J. (1997). Allometry for sexual size dimorphism: pattern and process in the coevolution of body size in males and females. Annual Review of Ecology and Systematics 28: 659-687.

Fairbairn, D.J.; Blanckenhorn, W.U. \& SzeKELY, T. (2007). Sex, Size and Gender Roles: Evolutionary Studies of Sexual Dimorphism. Oxford University Press, Oxford, UK.

Farasat, H.; Akmali, V. \& Sharifi, M. (2016). Population genetic structure of the endangered Kaiser's mountain newt, Neurergus kaiseri (Amphibia: Salamandridae). PLoS One 11: e0149596.

Ficetola, G.F.; Bonardi, A.; Colleoni, E.; PADOA-Schioppa, E. \& ScAli, S. (2013). Evolution of sexual dimorphism in the number of tail vertebrae in salamanders: comparing multiple hypotheses. Evolutionary Biology 40: 220-227.

Fontenot, C.L., JR. \& Seigel, R.A. (2008). Sexual dimorphism in the three-toed Amphiuma, Amphiuma tridactylum: sexual selection or ecological causes. Copeia 2008: 39-42.

Gibbons, J.W. \& Lovich, J.E. (1990). Sexual dimorphism in turtles with emphasis on the slider turtle (Trachemys scripta). Herpetological Monographs 4: 1-29.

GvožDík, L. \& VAN DAMme, R. (2006). Triturus newts defy the running-swimming dilemma. Evolution 60: 2110-2121.

Halliday, T. \& Arano, B. (1991). Resolving the phylogeny of the European newts. Trends in Ecology and Evolution 6: 113-117.

Hasumi, M. (2001). Secondary sexual characteristics of the salamander Salamandrella keyserlingii: throat coloration. Herpetological Review 32: 223-225.

Hasumi, M. (2010). Age, body size, and sexual dimorphism in size and shape in Salamandrella keyserlingii (Caudata: Hynobiidae). Evolutionary Biology 37: 38-48.

Howard, R.D. \& KLuge, A.G. (1985). Proximate mechanisms of sexual selection in wood frogs. Evolution 39: 260-277.

IUCN (2018). The IUCN Red List of Threatened Species, Version 2018-1. International Union 
for Conservation of Nature and Natural Resources, Gland, Switzerland. Available at https://www.iucnredlist.org/. Accessed on 17 July 2018.

Ivanović, A. \& Kalezić, M.L. (2012). Sexual dimorphism in the skull geometry of newt species of Ichthyosaura, Triturus and Lissotriton (Salamandridae, Caudata, Amphibia). Zoomorphology 131: 69-78.

Ivanović, A.; Sotiropoulos, K.; Furtula, M.; DžUKić, G. \& KALEzić, M.L. (2008). Sexual size and shape evolution in European newts (Amphibia: Caudata: Salamandridae) on the Balkan Peninsula. Journal of Zoological Systematics and Evolutionary Research 46: 381387.

Jakob, C.; Seitz, A.; Crivelli, A.J. \& Miaud, C. (2002). Growth cycle of the marbled newt (Triturus marmoratus) in the Mediterranean region assessed by skeletochronology. Amphibia-Reptilia 23: 407-418.

Kalezic, M.L.; Crnobrnja, J.; Dorovic, A. \& Dzukic, G. (1992). Sexual size difference in Triturus newts: geographical variation in Yugoslav populations. Alytes 10: 63-80.

Kaliontzopoulou, A.; Carretero, M.A. \& Llorente, G.A. (2007). Multivariate and geometric morphometrics in the analysis of sexual dimorphism variation in Podarcis lizards. Journal of Morphology 268: 152-165.

Kupfer, A. (2007). Sexual size dimorphism in amphibians: an overview, In D.J. Fairbairn, W.U. Blanckenhorn \& T. Szèkely (eds.) Sex, Size and Gender Roles. Evolutionary Studies of Sexual Size Dimorphism. Oxford University Press, Oxford, UK, pp. 50-59.

Liv, C.C.; Hu, S.Q. \& YANG, F.H. (1960). Amphibians from Wushan, Szechwan. Acta Zoologica Sinica 12: 278-293.

Lizana, M.; Ciudad, M.J. \& Pérez-Mellado, V. (1986). Uso de los recursos tróficos en una comunidad ibérica de anfibios. Revista Española de Herpetología 1: 209-271.

Malmgren, J.C. \& Thollesson, M. (1999). Sexual size and shape dimorphism in two species of newts, Triturus cristatus and T. vul- garis (Caudata: Salamandridae). Journal of Zoology 249: 127-136.

Marvin, G.A. (2009). Sexual and seasonal dimorphism in the Cumberland Plateau woodland salamander, Plethodon kentucki (Caudata: Plethodontidae). Copeia 2009: 227 -232 .

Marzona, E.; Seglie, D. \& Giacoma, C. (2004). Sexual dimorphism in body size and lifehistory traits in a population of Triturus alpestris alpestris. Italian Journal of Zoology 71: S117-S120.

Öztuna, D.; Elhan, A.H. \& TüCCAR, E. (2006). Investigation of four different normality tests in terms of type 1 error rate and power under different distributions. Turkish Journal of Medical Science 36: 171-176.

Rastegar-Pouyani, N.; Takesh, M.; Fattahi, A. \& Brown, R. (2013). Sexual size dimorphism in the yellow-spotted newt, Neurergus microspilotus Nesterov, 1916 (Caudata: Salamandridae), from Kermanshah Province, Western Iran. Russian Journal of Herpetology 20: 51-55.

Reinhard, S. \& Kupfer, A. (2013). Evolution des Sexualdimorphismus und der Lebensstrategien der Salamandridae. Amphibia 12: 1826.

Reinhard, S. \& Kupfer, A. (2015). Sexual dimorphism in a French population of the marbled newt, Triturus marmoratus (Urodela: Salamandridae). Salamand ra 51: 121-128.

Romano, A.; Bruni, G. \& Paoletti, C. (2009). Sexual dimorphism in the Italian endemic species Salamandrina perspicillata (Savi, 1821) and testing of a field method for sexing salamanders. Amphibia-Reptilia 30: 425434.

Romano, A.; Salvidio, S.; Palozzi, R. \& SbordoNI, V. (2012). Diet of the newt, Triturus carnifex (Laurenti, 1768), in the flooded karst sinkhole Pozzo del Merro, central Italy. Journal of Cave and Karst Studies 74: 271-277.

SAlvidio, S. \& BRUCE, R.C. (2006). Sexual dimorphism in two species of European plethodontid salamanders, genus Speleomantes. 
Herpetological Journal 16: 9-14.

Schmidt, K. (1952). Diagnoses of new amphibians and reptiles from Iran. Natural History Miscellanea 93: 1-2.

Seglie, D.; Roy, D. \& Giacoma, C. (2010). Sexual dimorphism and age structure in a population of Tylototriton verrucosus (Amphibia: Salamandridae) from the Himalayan Region. Copeia 4: 600-608.

Selander, R.K. (1972). Sexual selection and dimorphism in birds, In B. Campbell (ed.) Sexual Selection and the Descent of Man. Aldine Publishing Company, Chicago, Illinois, USA, pp. 180-230.

Serra-Сobo, J.; Uiblein, F. \& Martínez-Rica, J.P. (2000). Variation in sexual dimorphism between two populations of the Pyrenean salamander Euproctus asper from ecologically different mountain sites. Belgian Journal of Zoology 130: 39-45.

Sharifi, M.; Farasat, H. \& VAisi, S. (2012). Sexual size dimorphism in Neurergus kaiseri (Caudata: Salamandridae) in south-western Zagros Mountains, Iran. Amphibian and Reptile Conservation 6: 1-8.
Shine, R. (1979). Sexual selection and sexual dimorphism in the Amphibia. Copeia 1979: 297-306.

Shine, R. (1988). The evolution of large body size in females: a critique of Darwin's "Fecundity advantage" model. The American Naturalist 131: 124-131.

Shine, R. (1989). Ecological causes for the evolution of sexual dimorphism: a review of the evidence. Quarterly Review of Biology 64: 419-461.

SLATKIn, M. (1984). Ecological causes of sexual dimorphism. Evolution 38: 622-630.

Sparreboom, M.; Steinfartz, S. \& Schultschik, G. (2000). Courtship behaviour of Neurergus (Caudata: Salamandridae). AmphibiaReptilia 22: 1-11.

Wells, K.D. (2007). The Ecology and Behavior of Amphibians. The University of Chicago Press, Chicago, Illinois, USA.

Zhang, X.; XIONG, J.L.; Lv, Y.Y.; Zhang, L. \& Sun, Y.Y. (2014). Sexual size and shape dimorphism in the Wushan salamander, Liua shihi (Liu, 1950) (Urodela: Hynobiidae). Italian Journal of Zoology 81: 368-373. 